\title{
Determination of Binding Constant of DNA-binding Drug to Target DNA by Surface Plasmon Resonance Biosensor Technology
}

\author{
Liang-Ping Lin ${ }^{1}$, Long-Sun Huang ${ }^{2}$, Chii-Wann Lin ${ }^{3}$, Chi-Kung Lee ${ }^{2}$, Ji-Liang Chen $^{1}$, \\ Su-Ming $\mathrm{Hsu}^{4}$, Shiming Lin ${ }^{5, *}$ \\ ${ }^{1}$ Institute of Microbiology \& Biochemistry, ${ }^{2}$ Institute of Applied Mechanics, ${ }^{3}$ Institute of Biomedical Engineering, \\ ${ }^{4}$ Institute of Pathology, ${ }^{5}$ Center for Optoelectronic Biomedicine, National Taiwan University, Taipei, Taiwan
}

\begin{abstract}
The experimental determination of the binding constant of a drug for its target molecule is of considerable importance. It is a basic experimental parameter in a variety of studies, such as the prediction of drug efficiency, or in the pharmacokinetic drug interaction. DNA-binding drugs have been reported to be able to interfere in a sequence dependent manner with biological functions such as topoisomerase activity, restriction of enzyme cleavage of DNA, protein-DNA interactions and the activity of transcription factors, leading to alteration of gene expression. This effect could have important practical application in the experimental therapy of human pathologies, including neoplastic diseases and viral, or microbial infections. The assessment of the biological activity of DNA-binding drugs by polymerase chain reaction, footprinting, gel retardation and in vitro transcription studies was recently reported. However, most of these techniques are steady-state methodologies and therefore are not suitable for an easy determination of the binding activity of DNAbinding drugs to target DNA and the stability of drugs-DNA complexes. Direct real-time observation and measurement of the interaction between DNA-binding drug and target DNA sequence is a subject of interest for drug discovery and development. The recent development of biosensors, based on surface plasmon resonance (SPR) technology, enables monitoring of a variety of biospecific interactions of DNA-binding drugs with target DNA elements in real-time. The present review is designed to indicate the theoretical background of SPR-based biosensor technology as well as to present the great variety of measurements and modes of interaction kinetics that can be performed with these techniques. In addition, some of the most recent studies in determining the binding constant and stoichiometry of DNA-binding drugs to target DNA with SPR technology are reviewed and the available theoretical aspects necessary for the comprehension of the experiments are provided.
\end{abstract}

Key Words: Surface plasmon resonance, DNA-binding drug, target DNA, binding constant, stoichiometry, binding ratio.

\section{INTRODUCTION}

The quantitative aspects of the interaction of target DNA and DNA-binding drug can be studied by the use of a variety of methods which utilize either thermodynamic or kinetic approaches. At equilibrium, the binding constant or affinity of DNA-drug reaction may be expressed as: $K=$ $[A B] /[A][B]$, where $A$ represents free DNA sites; $B$, free drug; $\mathrm{AB}$, the DNA-drug complex. It should thus be possible to study the interaction kinetics of this reaction by conventional techniques involving addition of reactants, mixing and the subsequent determination of the concentration of the reactants or products at time intervals thereafter. Unfortunately, this simple type of approach is not suitable for the study of the reactions between drugs and complex multivalent oligonucleotides. In some situations, the target DNA has two or multiple binding sites, each of which has a similar or different intrinsic affinity for binding independently to each drug molecule [1-10].

From the application of the law of mass action to the DNA-drug reaction, a variety of methods have been developed which facilitate experimental calculations of binding constants for the interaction between DNA-binding

*Address correspondence to this author at the Center for Optoelectronic Biomedicine, National Taiwan University / College of Medicine, Jen-Ai Road, 100 Taipei, Taiwan; Fax: +886-2-23949125; E-mail: sml@ntumc.org drug and target DNA. These include spectrophotometry [11], DNA footprinting [12], equilibrium dialysis, gel retardation studies [13], fluorescence quenching, thermal denaturation, and ultracentrifugation [14]. These techniques generally involve the use of labeled reagents or are limited to molecules with specific spectrophotometric or chromophoric characteristics or require a binding induced change in the physical properties of the DNA. For example, spectrophotometric methods require a perturbation in the UV-Vis absorption spectrum of the drug molecule. In situations where a spectrophotometric change is not measurable, equilibrium dialysis can be used; however, a radiolabeled compound is needed. DNA footprinting assays can be disadvantageous when large numbers of compounds need to be tested since electrophoretic mobilities are determined on polyacrylamide gels, which have limited sample number capacity. Quantitation of binding constants is difficult by this method, since it requires optimization of DNA digestion conditions and data interpretation, can be complicated by uneven loading of labeled probes on the gel [15].

Surface plasmon resonance (SPR) biosensor technology has recently become an established method of measuring a variety of biomolecular interactions in real time. It is capable of characterizing binding reactions without labeling requirements. In a typical SPR experimental set-up, incident light is reflected from the internal face of a prism in which 
the external face has been coated with a thin metal film "Fig. (1)". At a critical angle, the intensity of the reflected light is lost to the creation of a resonant oscillation in the electrons at the surface of the metal film [16]. Since the critical angle is dependent on the refractive index of the material present on the metal surface, this real-time method has been used to measure molecular interactions at solid-liquid interface. One reactant, referred to as the ligand, is immobilized to the sensor surface and the other reactant, referred to as the analyte, flows past this surface in solution. When the analyte and the ligand interact to form a complex, a response is generated and monitored in real-time. SPR biosensors measure the change in refractive index in the vicinity of the surface of sensor chips to which ligands are immobilized [17]. Because the changes in the refractive index are proportional to the changes in the adsorbed mass, the SPR technology allows detection of analytes interacting with the ligand immobilized on the sensor chip. It can thus be used to study the interactions of any biological system from oligonucleotides, oligosaccharides, proteins, and lipids to small molecules, viral particles, and bacterial cells. More fundamentally, the technique allows the direct observation of association and dissociation rate constants that contribute to the overall binding affinity.

The use of SPR for the measurement of binding parameters for interactions has been reported. Qualitative applications range from following purification [18], epitope mapping [19], ligand fishing [20] to identifying small molecule leads in a screening mode [21]. Quantitative applications include measuring reaction kinetics $\left(k_{\mathrm{a}}, k_{\mathrm{d}}\right)$ [22] and binding constants $\left(K_{\mathrm{D}}\right)[23]$ and determining the active concentration of molecules [24]. Thermodynamic information can be obtained by measuring reaction rates and equilibrium constants at different temperatures [25]. When experiments are performed carefully, SPR biosensors can also be used to determine the binding stoichiometry and mechanism of the interaction [22].

The recent development of SPR-based biosensor technologies has made it possible to directly monitor the binding of low molecular mass compounds to immobilized macromolecules and thus allowed the study of fast molecular interaction kinetics and the evaluation of binding constants for DNA-drug interactions in free solution [1, 3-10, 26-29] "Table 1". In these reports, the simpler DNA-drug interaction can be sufficiently described by a 1:1 stoichiometry [28]. However, the determination of the binding constant of drug is complicated by the multivalence (multiple binding-sites) of the target DNA. When the drug is monovalent, aggregates will not come up for a monovalent DNA. For (homo) polyvalent DNA [5, 9-10]; however, aggregates can be formed depending on conditions. The problem of aggregation can be minimized by the use of a very low concentration of reactants or by performing the determination with a analyte excess. In addition, in some situations, the target oligonucleotides have two or multiple binding sites, each of which has a similar or different intrinsic affinity for binding independently to each drug molecule [1-4, 6-9]. It is not always easy to determine each of the intrinsic affinity. The problem of the heterogeneity of affinity of multivalent oligonucleotides still remains an obstacle to meaningful interpretation of data obtained. This review starts with the stoichiometry analysis of DNA-drug interaction kinetics by SPR biosensor and follows with an in-depth description

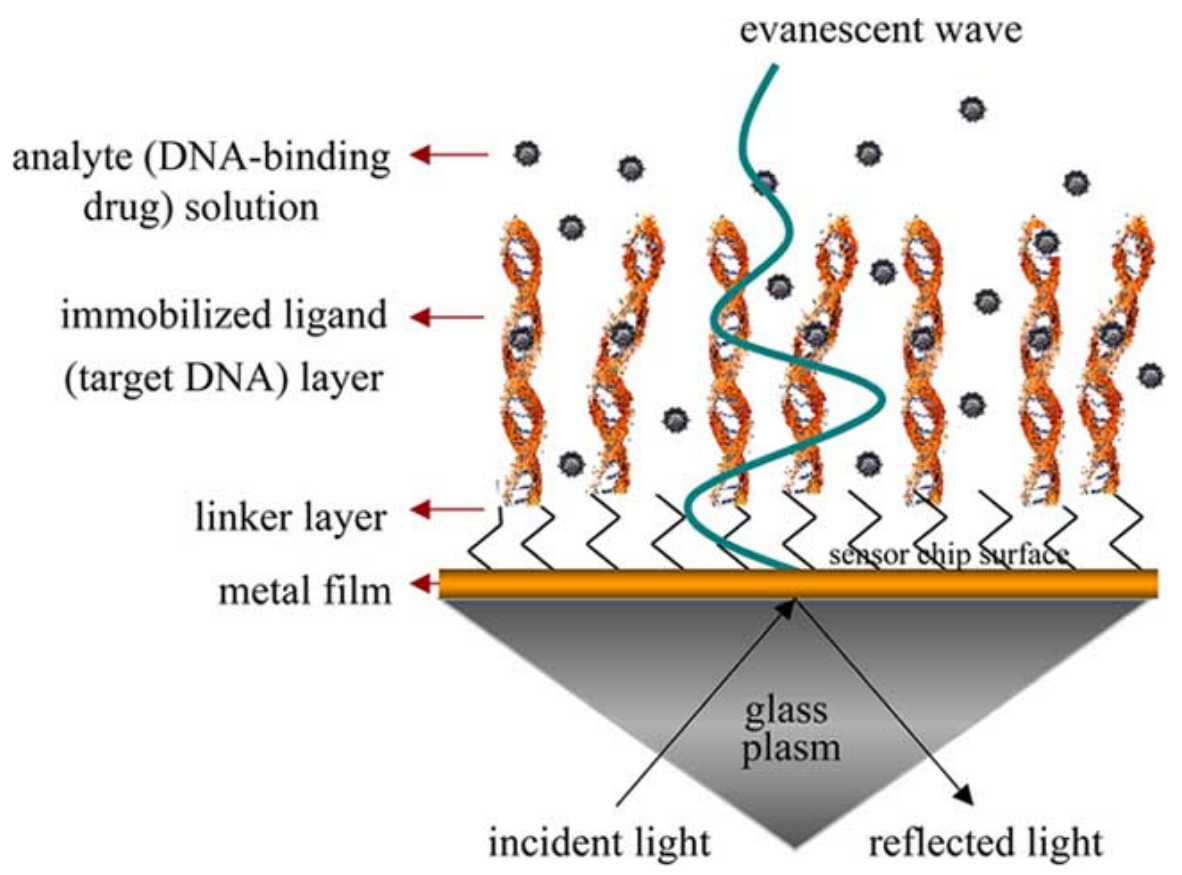

Fig. (1). In real-time biospecific interaction analysis, the binding events are detected using the optical phenomenon surface plasmon resonance, SPR. Under the conditions of total internal reflection at a metal-coated interface, an evanescent wave propagates into the medium of low refractive index on the non-illuminated side. The SPR response is correlated to changes in refractive index at the sensor chip surface, caused by concentration changes on the sensor chip surface, e.g., when the analyte (DNA-binding drug) binds to the immobilized ligand (target DNA). The SPR signal is monitored continuously so that interactions between analyte and ligand can be studied in real time. 
Table 1. SPR-based Studies of Biospecific Interaction Analysis Between DNA-binding Drugs and Target DNA Sequences.

\begin{tabular}{|c|c|c|c|c|c|}
\hline $\begin{array}{l}\text { Analyte (DNA- } \\
\text { binding drug) }\end{array}$ & Ligand (target DNA) & $K_{\mathrm{b}}\left(\mathbf{M}^{-1}\right)^{\mathrm{a}}$ & $K_{\mathrm{b}}\left(\mathbf{M}^{-1}\right)^{\mathrm{b}}$ & $n^{\mathrm{c}}$ & Ref. \\
\hline Sandramycin & $\begin{array}{l}\text { 5'-d(GCATGCTTTTGCATGC) } \\
\text { 5'-d(GCGCGCTTTTGCGCGC) } \\
\text { 5'-d(GCCGGCTTTTGCCGGC) } \\
\text { 5'-d(GCTAGCTTTTGCTAGC) }\end{array}$ & $\begin{array}{l}9.0 \times 10^{7} \\
3.8 \times 10^{7} \\
2.5 \times 10^{7} \\
2.3 \times 10^{7}\end{array}$ & $\begin{array}{l}7.8 \times 10^{7} \\
4.0 \times 10^{7} \\
1.5 \times 10^{7} \\
1.8 \times 10^{7}\end{array}$ & $\begin{array}{l}1.0 \\
1.0 \\
0.83 \\
0.83\end{array}$ & {$[28]$} \\
\hline Actinomycin & 47 bp DNA sequence including five G-C sites & & $1.9 \times 10^{6}$ & & [27] \\
\hline Mithramycin & HIV-1 Sp1 DNA & & & 6 & [26] \\
\hline Distamycin & HIV-1NF-kB DNA & & & 5 & [26] \\
\hline $\begin{array}{c}\text { Carbazole dication } \\
\text { derivatives }\end{array}$ & $\begin{array}{l}\text { DNA hairpin oligomer with stem sequences } \\
\text { CGAATTCG }\end{array}$ & & $\begin{array}{l}K_{1}=1.2 \sim 6.1 \times 10^{6} \\
K_{2}=2.5 \sim 4.2 \times 10^{5}\end{array}$ & 1.4 & [1] \\
\hline $\begin{array}{l}\text { DB293 (aromatic } \\
\text { dication) }\end{array}$ & Oligo2-1 hairpin duplex & & $K_{1}=2.8 \times 10^{6}, K_{2}=7.3 \times 10^{7}$ & 2 & {$[2]$} \\
\hline DB293 derivative & CTATGAC-containing Oligo2-1 & & $K_{1}=1.38 \times 10^{7}, K_{2}=6.20 \times 10^{7}$ & 2 & {$[6]$} \\
\hline DB293 derivative & AATT- containing Oligo1 & & $K_{1}=3.11 \times 10^{7}, K_{2}=1.22 \times 10^{4}$ & 1 & {$[6]$} \\
\hline $\begin{array}{c}\text { DB358 } \\
\text { (trithiophene } \\
\text { derivates of } \\
\text { furimidazoline) }\end{array}$ & $\begin{array}{c}\text { AT, AATT, and GC-containing hairpin loop } \\
\text { DNA sequence }\end{array}$ & & $\begin{array}{l}1.7 \times 10^{6}, 1.4 \times 10^{6}, 0.6 \times 10^{6} \\
\text { respectively }\end{array}$ & 3 & {$[5]$} \\
\hline $\begin{array}{c}\text { Acridine derivative } \\
1,2,3,4\end{array}$ & $\mathrm{~d}\left(\mathrm{AG}_{3}\left[\mathrm{~T}_{2} \mathrm{AG}_{3}\right]_{3}\right)$ duplex sequence & $\begin{array}{c}1.1 \times 10^{6} \\
2 \times 10^{5} \\
4 \times 10^{5} \\
5 \times 10^{5}\end{array}$ & & & [29] \\
\hline $\begin{array}{c}\text { Acridine derivative } \\
1,2,3,4\end{array}$ & $\mathrm{~d}\left(\mathrm{AG}_{3}\left[\mathrm{~T}_{2} \mathrm{AG}_{3}\right]_{3}\right)$ quadruplex sequence & $\begin{array}{l}1.3 \times 10^{6} \\
8.3 \times 10^{5} \\
1.6 \times 10^{7} \\
1.6 \times 10^{7}\end{array}$ & & & [29] \\
\hline $\begin{array}{l}2,7 \text { bis-amidine } \\
\text { carbazole }\end{array}$ & $\begin{array}{l}\text { d(CATATATATCCCCATATATATG) } \\
\text { d(CGCGCGCGTTTTCGCGCGCG) }\end{array}$ & & $\begin{array}{c}K_{1}=11.5 \times 10^{6} ; K_{2}=0.9 \times 10^{6} \\
K_{1}=2.5 \times 10^{5} ; K_{2}=0.8 \times 10^{5}\end{array}$ & & {$[3]$} \\
\hline $\begin{array}{l}3,6 \text { bis-amidine } \\
\text { carbazole }\end{array}$ & $\begin{array}{c}\text { d(CATATATATCCCCATATATATG) } \\
\text { d(CGCGCGCGTTTTCGCGCGCG) }\end{array}$ & & $\begin{array}{l}K_{1}=2.3 \times 10^{6} ; K_{2}=0.3 \times 10^{6} \\
K_{1}=4.7 \times 10^{5} ; K_{2}=1.1 \times 10^{5}\end{array}$ & & [3] \\
\hline $\begin{array}{l}\text { DB293(aromatic } \\
\quad \text { dication) }\end{array}$ & Various 13-bp sequences including ATGA motif & & $\begin{aligned} K_{1}= & 0.3 \sim 1.8 \times 10^{6} ; K_{2}= \\
& 4.1 \sim 9.5 \times 10^{7}\end{aligned}$ & 2 & [4] \\
\hline Ditercalinium & 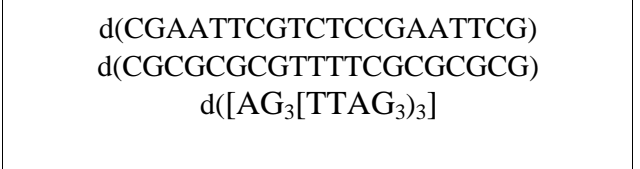 & $\begin{array}{l}0.9 \times 10^{7} \\
1.0 \times 10^{7} \\
3.0 \times 10^{7}\end{array}$ & & $\begin{array}{l}2 \\
2 \\
2\end{array}$ & {$[8]$} \\
\hline $\begin{array}{c}\text { AT2433-B1 } \\
\text { (indolocarbazole } \\
\text { aglycone compound) }\end{array}$ & $\begin{array}{l}\text { AT-rich DNA sequence } \\
\text { GC-rich DNA sequence }\end{array}$ & & $\begin{array}{l}13 \times 10^{5}\left(25^{\circ} \mathrm{C}\right), 15 \times 10^{5}\left(4^{\circ} \mathrm{C}\right) \\
89 \times 10^{5}\left(25^{\circ} \mathrm{C}\right), 76 \times 10^{5}\left(4^{\circ} \mathrm{C}\right)\end{array}$ & $\begin{array}{c}4-5 \\
3\end{array}$ & [9] \\
\hline $\begin{array}{l}\text { DB75-related } \\
\text { diphenylfuran } \\
\text { dications }\end{array}$ & $\begin{array}{l}\text { 5'-biotin-CATATATATCCCCATATATATG-3' } \\
\text { 5'-biotin-CGCGCGCGTTTTCGCGCGCG-3' }\end{array}$ & & & & [7] \\
\hline
\end{tabular}


(Table 1. Contd....)

\begin{tabular}{|c|c|c|c|c|c|}
\hline $\begin{array}{l}\text { Analyte (DNA- } \\
\text { binding drug) }\end{array}$ & Ligand (target DNA) & $K_{\mathrm{b}}\left(\mathbf{M}^{-1}\right)^{\mathrm{a}}$ & $K_{\mathrm{b}}\left(\mathbf{M}^{-1}\right)^{\mathrm{b}}$ & $n^{c}$ & Ref. \\
\hline $\begin{array}{c}\text { Macrocyclic } \\
\text { compound BOQ1 }\end{array}$ & 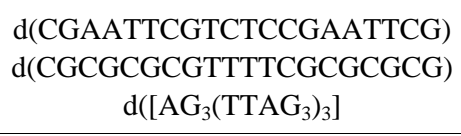 & & $\begin{array}{l}1.1 \times 10^{6} \\
1.5 \times 10^{6} \\
1.2 \times 10^{7}\end{array}$ & $\begin{array}{l}2 \\
2 \\
2\end{array}$ & [10] \\
\hline $\begin{array}{c}\text { Macrocyclic } \\
\text { monomer MOQ2 }\end{array}$ & 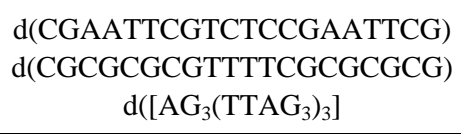 & & $\begin{array}{l}1.1 \times 10^{6} \\
1.9 \times 10^{6} \\
1.4 \times 10^{6}\end{array}$ & $\begin{array}{c}1 \\
1-2 \\
2\end{array}$ & {$[10]$} \\
\hline $\begin{array}{c}\text { Macrocyclic } \\
\text { monomer MMQ1 }\end{array}$ & 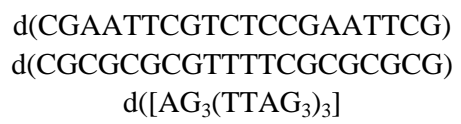 & & $\begin{array}{l}4.7 \times 10^{5} \\
4.1 \times 10^{5} \\
8.6 \times 10^{5}\end{array}$ & $\begin{array}{c}3 \\
4-5 \\
4\end{array}$ & [10] \\
\hline
\end{tabular}

${ }^{a}$ Binding constant calculated as $K_{\mathrm{b}}=k_{\mathrm{a}} / k_{\mathrm{d}}$

${ }^{\mathrm{b}}$ Steady state Binding constant calculated as $R / C=K_{\mathrm{b}} R_{\max }-K_{\mathrm{b}} R$

${ }^{\mathrm{c}}$ Stoichiometry of binding

about the quantitative expression and evaluation of binding constants for DNA-drug interaction kinetics by SPR method, with particular emphasis on the non-cooperativity and cooperativity of two binding sites on the divalent DNA.

\section{PRINCIPLE OF REAL-TIME DNA-DRUG INTERACTION KINETICS}

In SPR biosensors, one of the reactants, for example target DNA (ligand), is immobilized on a sensor chip. The other reactant, DNA-binding drug (analyte), enters at one end, is transported by diffusion and flow to the sensor surface, where it reacts with immobilized target DNA "Fig. (2A)". Change in the resonance signal expressed as resonance units (RU) are followed as a function of time and presented as a sensorgram "Fig. (2B)". From this data, binding kinetics of the DNA-drug interaction can be determined. The formation of surface-bound complex $A B$ in
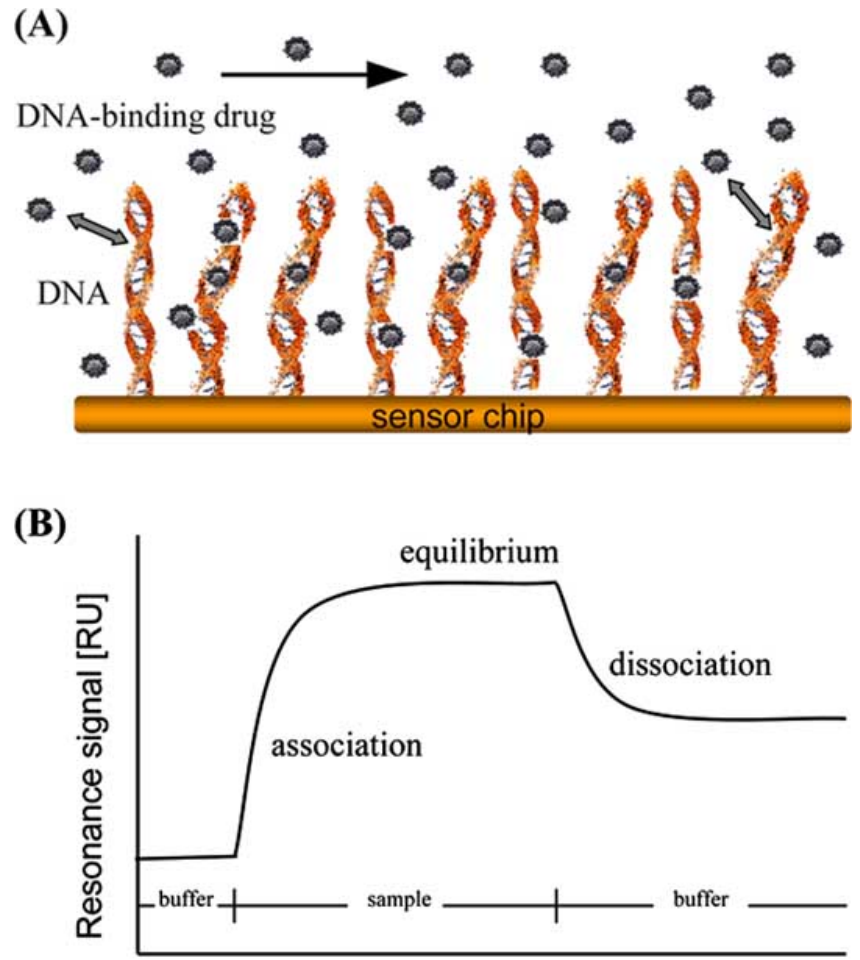

Time [s]

Fig. (2). (A) Schematic diagram depicting the interaction of analyte (DNA-binding drug) with ligand (target DNA) at liquid-solid interface. (B) Schematic sensorgram, showing association, equilibrium and dissociation phases. When analyte is injected in a discrete pulse across an ligand surface, the resulting sensorgram can be divided into three essential phases: (1) Association of analyte with DNA during sample injection; (2) Equilibrium or steady state during sample injection, where the rate of analyte binding is balanced by dissociation from the complex; (3) Dissociation of analyte from the surface during buffer flow. 
the flow cell between analyte A and surface-bound ligand B can be represented by the scheme

$$
\mathrm{A}_{\text {bulk }} \underset{K_{\mathrm{m}}}{\stackrel{K_{\mathrm{m}}}{\longrightarrow}} \mathrm{A}_{\text {surface }}+\mathrm{B} \underset{K_{\mathrm{b}}}{\stackrel{K_{\mathrm{a}}}{=}} \mathrm{AB}
$$

where $k_{\mathrm{m}}$ is the rate constant for mass transport to and from the surface (the rate constant for mass transport is the same in both directions) and $k_{\mathrm{a}}$ and $k_{\mathrm{d}}$ are the rate constants for the formation of DNA-drug complex.

In the ideal situation, neither the transport of DNAbinding drug to the sensor surface, nor its transport within the linker layer influences the binding kinetics. This happens when transport is fast compared to binding. In this case, the DNA-binding drug concentration rapidly becomes uniform in space and constant in time, equals to the injection concentration $[\mathrm{B}]_{\mathrm{o}}$ in the bulk phase, and the measured forward and backward rate constants approximate to the constants for interaction kinetics [30]. Under these conditions, the rate of complex formation may be as

$$
\mathrm{d}[\mathrm{AB}] / \mathrm{d} t=k_{\mathrm{a}}[\mathrm{A}]\left([\mathrm{B}]_{\mathrm{o}}-[\mathrm{AB}]\right)-k_{\mathrm{d}}[\mathrm{AB}]
$$

where $[\mathrm{AB}]$ is the amount of bound analyte, $[\mathrm{A}]$ is the free analyte amount, $[\mathrm{B}]_{\mathrm{o}}$ is the total amount of ligand on the sensor surface. The on and off rates of binding are directly observable and the binding constants may be calculated by two methods described below.

\subsection{Equilibrium Analysis}

If the total amount of ligand $[\mathrm{B}]_{\mathrm{o}}$ is expressed in terms of the maximum analyte binding capacity of the surface, i.e., the total amount of DNA binding-site on the sensor surface, all concentration terms can then be expressed as SPR response signal $R$, eliminating the need to convert from mass to molar concentration. Under pseudo first order conditions where the free analyte concentration is held constant in the flow cell, the binding can is described by Eq. [3]:

$\mathrm{d} R / \mathrm{d} t=k_{\mathrm{a}} C\left(R_{\max }-R\right)-k_{\mathrm{d}} R$

where $\mathrm{d} R / \mathrm{d} t$ is the rate of change of the SPR response signal, $R$ and $R_{\max }$ are the measured and maximum response signal measured with binding, $C$ is the injected concentration of the drug analyte $(\mathrm{M}), k_{\mathrm{a}}$ is the association rate constant or on-rate $\left(\mathrm{M}^{-1} \mathrm{~s}^{-1}\right)$ and $k_{\mathrm{d}}$ is the dissociation rate or off-rate $\left(\mathrm{s}^{-1}\right)$ "Fig. (3A)". The binding constant, i.e., association constants $K_{\mathrm{A}}$, may be calculated as $K_{\mathrm{A}}=k_{\mathrm{a}} / k_{\mathrm{d}}\left(\mathrm{M}^{-1}\right)$. At equilibrium, $\mathrm{d} R / \mathrm{d} t=0$ and Eq. [3] can be rewritten:

$R_{\mathrm{eq}} / C=K_{\mathrm{A}} R_{\max }-K_{\mathrm{A}} R_{\mathrm{eq}}$

Therefore, the steady state association constant $K_{\mathrm{A}}$ can be obtained from a plot of $R_{\text {eq }} / C$ versus $R_{\text {eq }}$ and the dissociation constant $K_{\mathrm{D}}$ can be calculated as $1 / K_{\mathrm{A}}$ "Fig. (3B)".

\section{2. Association kinetics Analysis}

Equation [3] may be rearranged to give:

$\mathrm{d} R / \mathrm{dt}=k_{\mathrm{a}} C R_{\max }-\left(k_{\mathrm{a}} C+k_{\mathrm{d}}\right) R$
(A)

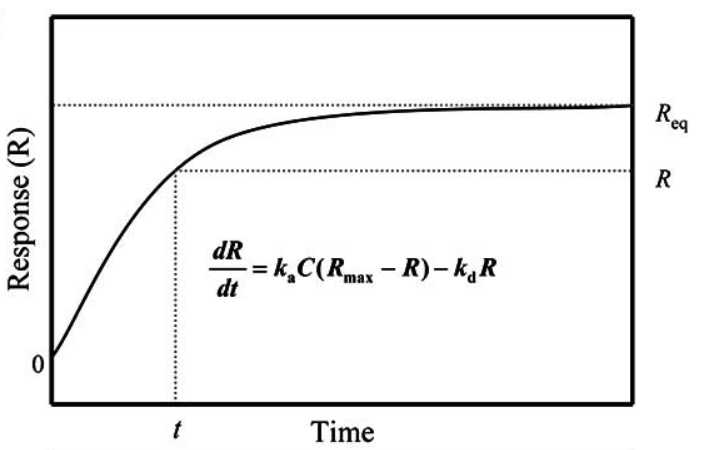

(B)

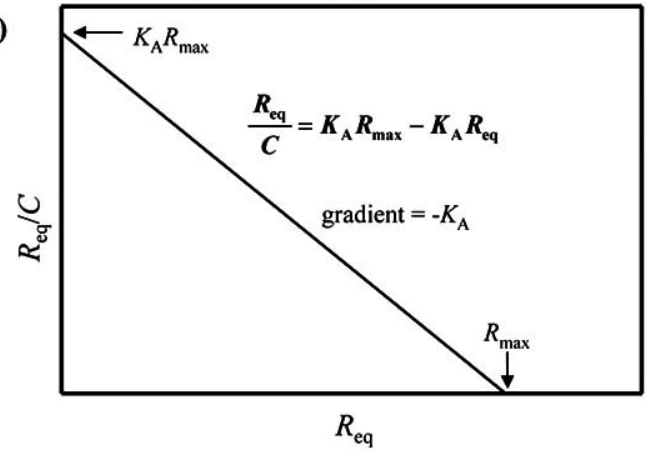

(C)

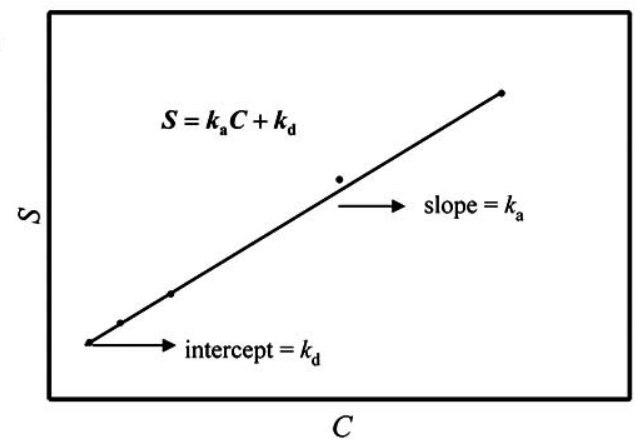

Fig. (3). (A) Simulated sensorgram illustrating affinity and kinetic measurement of DNA-drug interaction according to Eq. [3]. (B) A plot of $R_{\text {eq }} / C$ against $R_{\text {eq }}$ at different drug concentrations according to Eq. [4] thus gives a straight line from which $R_{\max }$ and $K_{\mathrm{A}}$ can be calculated. (C) A plot of slope value $S$ versus drug concentration $C$ according to Eq. [6].

Thus a plot of $\mathrm{d} R / \mathrm{dt}$ against will theoretically be a straight line with slope $-\left(k_{\mathrm{a}} C+k_{\mathrm{d}}\right)$ for interaction-controlled kinetics. The initial binding rate (at $\mathrm{R}=0$ ) is directly proportional to the analyte concentration and can be used for concentration measurements. If $R_{\max }$ is known, both $k_{\mathrm{a}}$ and $k_{\mathrm{d}}$ can be determined from a single association sensorgram. $R_{\max }$ is however often difficult to determine experimentally, since a high analyte concentration is required to fully saturate the surface. A preferable approach is to measure the association sensorgram at several different analyte concentrations. For analysis of the on and off rates, a plot of the change in total detector response $\left(\mathrm{d} R / \mathrm{d}_{t}\right)$ versus $R$ gives a value $S$ as the slope which relates the on and off rates as follows:

$S=k_{\mathrm{a}} C+k_{\mathrm{d}}$

A plot of $S$ against $C$ will be a straight line with slope $k_{\text {a }}$ "Fig. (3C)". In theory, the intercept on the ordinate $(C=0)$ 
give $k_{\mathrm{d}}$ : in practice, however, this cannot be used as a reliable measure of the dissociation rate constant if $k_{\mathrm{a}} C \gg k_{\mathrm{d}}$. A more accurate way to obtain this value is by direct measurement of the dissociation from saturated binding sites into a buffer solution flow that contains no drug analyte and the dissociation is quantified by:

$\ln \left(R_{\mathrm{o}} / R_{\mathrm{t}}\right)=k_{\mathrm{d}}\left(\mathrm{t}-\mathrm{t}_{\mathrm{o}}\right)$

where $R_{\mathrm{o}}$ is the initial response level at $\mathrm{t}_{\mathrm{o}}$ and $R$ and $\mathrm{t}$ represent values obtained along the dissociation curve.

\section{DETERMINATION OF STOICHIOMETRY}

\subsection{Data Analysis}

The apparent stoichiometry of the surface complex (i.e. the number of drug molecules that can bind to one DNA molecule) was calculated from the saturating binding capacity of the surface by the equation [31-33]:

stoichiometry $=\frac{R_{\text {drug }}}{R_{\text {DNA }}} \times \frac{M W \text { DNA }}{M W \text { drug }}=\frac{R_{\text {max }}-R_{i}}{R U_{i}-R_{0}} \times$

MW DNA

MW drug

where $R_{\mathrm{DNA}}$ is the SPR response of surface immobilized DNA in RUs. $R_{\text {drug }}$ is the observed response of bound drug. Relationship between bound drug $\left(R U_{\max }-R_{\mathrm{i}}\right)$ and amount of target DNA $\left(\mathrm{RU}_{\mathrm{i}}-\mathrm{RU}_{\mathrm{o}}\right)$ present on the sensor surface is displayed in "Fig. (4)".

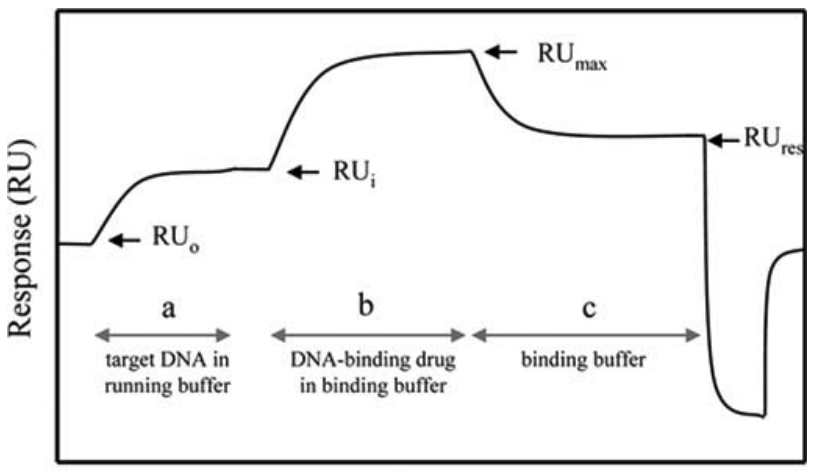

Time (sec)

Fig. (4). A simple simulated sensorgram illustrating the binding of a DNA-binding drug to a target DNA immobilized on a sensor chip. A running buffer solution is pumped at a constant flow rate over the sensor surface. The sensorgram shows that injection of target DNA generates an increase in the response expressed as resonance units (RU) $\left(R U_{i}-R_{o}\right)$. A pulse of sample is then injected and association of the drug analyte to the DNA ligand is shown in b. An increase $\left(R U_{\max }-R U_{i}\right)$ of resonance unit is observed following an injection of an analyte. The decrease of RU during the washing step (injection of binding buffer) is shown in c.

\subsection{Example}

Gambari and co-workers [26] demonstrated that molecular interactions between DNA-binding drugs (e.g., chromomycin, mithramycin, distamycin, and MEN 10567) and biotinylated target DNA probes, immobilized on sensor chips, are detectable by SPR technology using the BIAcore biosensor (Pharmacia Biosensors, Uppsala, Sweden). The target DNA sequences were synthetic oligonucleotides mimicking the Sp1, NF-kB, and TFIID binding sites of the long terminal repeat of the human immunodeficiency type 1 virus. They detected the binding activity of two $\mathrm{G}+\mathrm{C}$ selective minor groove ligands, mithramycin and chromomycin, and two A+T selective binders, distamycin and MEN 10567. The results obtained demonstrate that mithramycin/DNA complexes are less stable than chromomycin/DNA complexes; distamycin binds to both NF-kB and TATA box oligonucleotides, but distamycin/(NFkB) DNA complexes are not stable; the distamycin analogue MEN 10567 binds to the NF-kB mer and the generated drug/DNA complexes are stable. The experimental approach described in this literature allows fast analysis of molecular interaction stoichiometry between DNA-binding drugs and selected target DNA sequences. As shown in "Fig. (5)", for example, the apparent stoichiometry of the surface DNA-drug complexes was calculated from the saturating binding capacity of the SASp1 mer surface, considering 1,085 and 7,505 Da the molecular weights of the drug (mithramycin) and target DNA (Sp1c mer). The obtained data gave evidence for a $6: 1$ (drug: DNA) stoichiometry in most of the experiments performed (average 5.7:1). This result was proven to be consistent with a large number of NMR studies indicating that mithramycin and the analogue chromomycin bind as a symmetric dimer to self complementary target hexanucleotide and octanucleotide complexes.

\section{DETERMINATION OF MAXIMUM BINDING RATIO}

\subsection{Data Analysis}

The measured SPR response in resonance units (RUs) is assumed to correlate to the surface concentration of immobilized target DNA and drug bound using the estimate $1 \mathrm{RU} \approx 1 \mathrm{pg} \mathrm{mm}^{-2}$ as has been done in the past for proteins and oligonucleotides [34]. Because of this, the $R_{\max }$ value can be used to calculate a maximum binding ratio (mol drug bound/mol DNA immobilized), assuming one set of independent noninteracting binding sites, using the following equation:

maximum binding ratio $=\frac{\mathrm{R}_{\max }}{\mathrm{R}_{\mathrm{DNA}}} \times \frac{\mathrm{MW} \mathrm{DNA}}{\mathrm{MW} \text { drug }} \times \frac{1}{\mathrm{n}}$

where $R_{\mathrm{DNA}}$ is the amount of surface immobilized DNA in RUs and $n$ is the number of binding sites on the target DNA. $R_{\max }$ is the maximum response at saturation of surface binding sites and can be determined by the method described below.

At equilibrium, $\mathrm{d} R / \mathrm{d} t=0$ and Eq. [3] can be rearranged:

$R_{\mathrm{eq}}=\left(R_{\max } K_{\mathrm{A}} C\right) /\left(1+K_{\mathrm{A}} C\right)$

where $C$ is the concentration of drug injected, $K_{\mathrm{A}}$ is the apparent association constant. $R_{\text {eq }}$ is the measured response at equilibrium, and values of $R_{\text {eq }}$ are obtained at a series of injected analyte $C$ solution concentrations. The steady state 


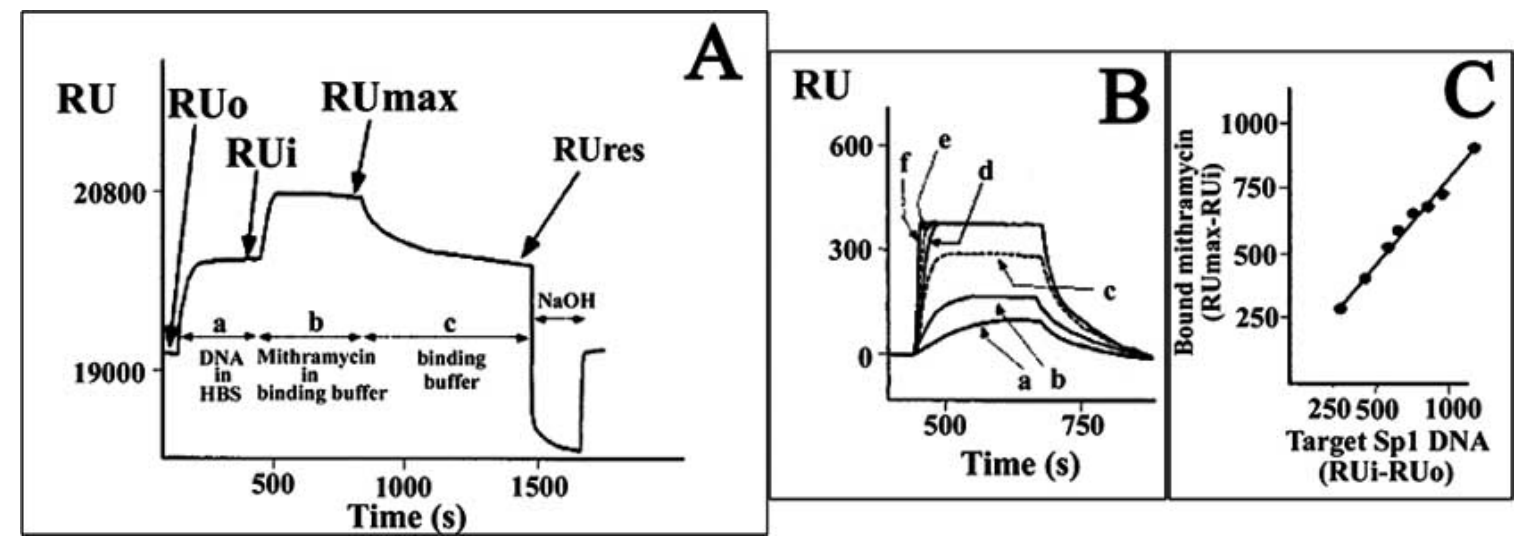

Fig. (5). (A) The sensogram for the binding of mithramycin to double-stranded HIV-1 Sp1 DNA. (B) The binding of mithramycin to target Sp1 DNA was studied at different drug concentrations $(0.5-8 \mathrm{mM})$. The sensorgrams obtained were analysed and the values of $\mathrm{RU}_{\max }-\mathrm{RU}_{\mathrm{i}}$ for mithramycin were found to be in nine different experiments, $825 \pm 133 \mathrm{RU} / 1000 \mathrm{RU}$ of Sp1c mer immobilized on the SA5 sensor chip. (C) When the same concentration of mithramycin was injected to flow cells containing increased amounts of target Sp1 double-stranded oligonucleotide, a direct relationship was found between $\mathrm{RU}_{\max }-\mathrm{RU}_{\mathrm{i}}$ values and amounts of $\mathrm{Sp} 1$ mer immobilized on the sensor chip $\left(\mathrm{RU} \mathrm{U}_{\mathrm{i}}\right.$ $\mathrm{RU}_{\mathrm{o}}$ ). Adapted from [26].

response can be plotted versus the analyte concentration and the data are fit to a simple Langmuir isotherm for molecular interactions "Fig. (6A)". $R_{\max }$ can then be calculated from the best fit of the binding curve.

Thus, the maximum binding ratio (drug molecules per target DNA) can be calculated by Eq. [9] using the $R_{\max }$ obtained by Eq. [10] and the known amount of DNA immobilized.

\subsection{Examples}

Ciolkowski and co-workers [27] reported a simple and general SPR based method to detect and quantitate binding of low molecular weight anti-tumoral agents to double stranded DNA. The binding of actinomycin (MW $1255 \mathrm{Da}$ ), an anti-tumor antibiotic known to bind DNA through intercalation binding and minor groove binding, was investigated. The biological activity of actinomycin is believed to be due to its ability to bind to duplex DNA and thereby inhibit DNA dependent RNA polymerase. The binding of actinomycin to the 47 bp DNA probe was measured at concentrations ranging from 0.82 to $6.6 \mathrm{mM}$ "Fig. (6B)". Analysis of the binding curve yielded $K_{\mathrm{A}}=1.9 \mathrm{x}$ $10^{6} \mathrm{M}^{-1}$ and $R_{\max }=321$ RUs. Actinomycin is known to intercalate and bind strongly to G-C containing sites on DNA [35-36]. The 47 bp DNA probe, used in these experiments, contains five G-C sites. The maximum binding ratio (actinomycin molecules per bp) was calculated by Eq. [9] using the $R_{\max }$ obtained from the best fit of the actinomycin binding curve "Fig. (6B)" and the known amount of DNA immobilized. The binding ratio was 0.14 or $\approx 1 \mathrm{drug} / 4 \mathrm{bp}$. If actinomycin bound to all G-C sites present in the DNA probe then the binding ratio would be expected to be $\sim 0.1$. Since the estimated binding ratio is close to 0.1 it may suggest that binding occurred at G-C sites.

\section{ONE TO ONE INTERACTION MODE}

\subsection{Data Analysis}

The theory of kinetic measurements for a DNA-drug reaction, analyzed in terms of one to one interaction model, has been described by Boger and Saionz [28]. The

(B)
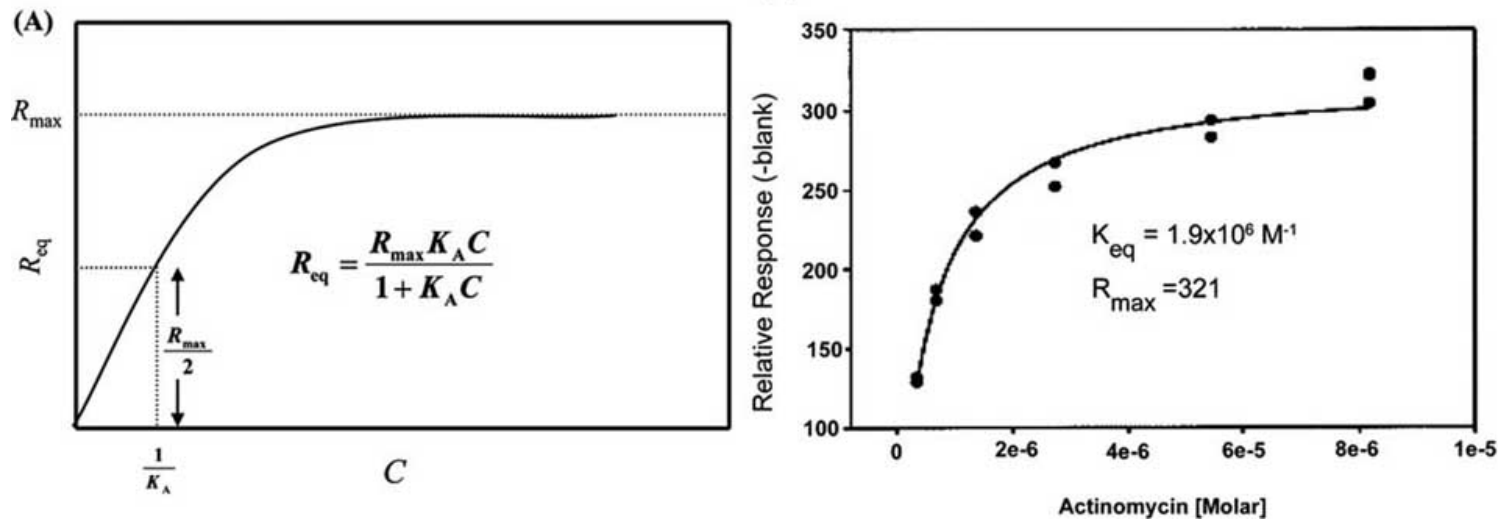

Fig. (6). (A) A binding curve of the steady state binding response $R_{\text {eq }}$ versus drug concentration $C$ according to Eq. [10]. (B) Steady state binding response versus concentration for actinomycin binding to the $47 \mathrm{bp}$ DNA surface. Actinomycin concentrations ranged from 0.82 to $6.6 \mathrm{mM}$. The DNA surface immobilization level was $\approx 1126$ RUs. Adapted from [27]. 
association rate constant, $k_{\mathrm{a}}$, can be determined by carrying out a series of interaction experiments with different drug concentration $(C)$ and by measuring the binding rate, $\mathrm{d} R / \mathrm{d} t$, as a function of the SPR response $(R)$ (Eq. 5). Using linear transformation of the primary data, plots of $\mathrm{d} R / \mathrm{d} t$ versus $\mathrm{R}$ are made for a range of drug concentrations and the slopes of these curves, $S=k_{\mathrm{a}} C+k_{\mathrm{d}}$ (Eq. [6]), are determined. The $S$ values are then plotted versus concentrations, and the new line obtained will have a slope corresponding to $k_{\mathrm{a}}$. The dissociation rate constant, $k_{\mathrm{d}}$, can be calculated from the dissociation phase described by Eq. [7]. A plot of $\ln \left(R_{\mathrm{o}} / R_{\mathrm{t}}\right)$ versus $t-t_{\mathrm{o}}$ gives a straight line with slope $k_{\mathrm{d}}$. The apparent binding (or association) constant, $K_{\mathrm{A}}$, for the DNA-drug interaction can then be determined as the ratio $K_{\mathrm{A}}=k_{\mathrm{a}} / k_{\mathrm{d}}$ (or dissociation constant $K_{\mathrm{D}}=k_{\mathrm{d}} / k_{\mathrm{a}}$ ).

\subsection{Examples}

Boger and Saionz [28] employed SPR biosensor technique to establish the DNA binding affinity of sandramycin and a key series of chromophore analogues within 5'-d(GCXXGC) $)_{2}$ where XX=AT, TA, GC, and CG. Sandramycin, a potent antitumor antibiotic agent, possesses a two-fold axis of symmetry and two heteroaromatic chromophores and which results in sequence-selective DNA bis-intercalation spanning two base-pairs preferentially at 5'AT sites. With the studies, the determination of absolute binding constants "Table 1" within a single high affinity bisintercalation site permitted a quantitative assessment of the sequence selectivity of sandramycin as $5^{\prime}-\mathrm{d}(\text { GCATGC })_{2}>$ $5^{\prime}-\mathrm{d}(\mathrm{GCGCGC})_{2}, \Delta \Delta \mathrm{G}^{\mathrm{o}}=0.4 \mathrm{kcal} / \mathrm{mol} \geq 5^{\prime}-\mathrm{d}(\text { GCTAGC })_{2}$, $\Delta \Delta \mathrm{G}^{\mathrm{o}}=0.9 \mathrm{kcal} / \mathrm{mol} \geq 5^{\prime}-\mathrm{d}(\mathrm{GCCGGC}), \Delta \Delta \mathrm{G}^{\mathrm{o}}=1.0 \mathrm{kcal} / \mathrm{mol}$ and a quantitative assessment of the chromophore structural features contributing to binding at a single high affinity bisintercalation site. The results obtained by SPR parallel and those derived from fluorescence quenching studies also suggest that sandramycin is best represented as a DNA minor groove binding cyclic decadepsipeptide incrementally stabilized by mono- and bis-intercalation.

Since the runs were allowed to reach equilibrium, on rates $\left(k_{\mathrm{a}}\right)$ and $S$ values as well as $R_{\max }$ values could be obtained from each. This allowed comparison of on rates at a variety of concentrations and their determination by a plot of $S$ versus $C$ according to $\mathrm{Eq}$ [6]. The off rates were determined according to $\mathrm{Eq}$ [7] and also compared to the $y$ intercept of the plot of Eq [6]. The binding constant $K_{\mathrm{b}}$ (i.e., association constant) could be obtained from the ratio $k_{\mathrm{a}} / k_{\mathrm{b}}$ and these values are presented in Table 1. A second method of determining $K_{\mathrm{b}}$ is by a plot of $R / C$ against $R$ according to Eq. [4] and this is also presented in Table 1. Given the exceptionally slow off rates for many of the agents, the latter approach to establishing $K_{\mathrm{b}}$ is presumed to provide the more reliable estimates.

\section{NONEQUIVALENT TWO-SITE INTERACTION MODE}

\subsection{Data Analysis}

The SPR response ( $\mathrm{R})$ in the steady-state region is proportional to the amount of bound drug. The maximum response per bound drug $\left(R_{\max }\right)$ in the steady-state region can be predicted by Eq [11]:
$R_{\max }=R_{\mathrm{DNA}} \mathrm{x}$ (MW drug / MW DNA) x RI

where $R_{\mathrm{DNA}}$ is the amount of surface immobilized DNA in RUs, the second term on the right side of Eq [11] is the ratio of molecular weights of the drug and DNA, and RI is the refractive index gradient ratio for the drug and DNA. The RI values can be measured by using differential refractometry method [37].

Steady-state binding analysis is performed with multiple injections of different drug concentrations over the immobilized DNA surface. Steady-state $R$ values can be converted to $r$, where $r=R / R_{\max }$, and the results can then be fit by nonlinear least squares methods to a two-site equilibrium model Eq. [12]:

$r=\left(K_{1} C+2 K_{1} K_{2} C^{2}\right) /\left(1+K_{1} C+K_{1} K_{2} C^{2}\right)$

where $r$ represents the moles of bound drug per mole of DNA molecule, $C$ is the unbound drug concentration in equilibrium with the DNA-drug complex and is fixed by the concentration in the flow solution. $K_{1}$ and $K_{2}$ values are the macroscopic equilibrium constants for binding to the two sites. When the observed $R$ values at high drug concentrations are greater than $R_{\max }$, the drugs must have at least two binding sites on this DNA sequence.

\subsection{Examples}

Furamidine and related diamidines represent a promising series of drugs active against widespread parasites, in particular the Pneumocystic carinii pathogen. In this series, the phenylfuranbenzimidazole diamidine derivative DB293 "Fig. (7A)" was recently identified as the first unfused aromatic dication capable of forming stacked dimers in the DNA minor groove of GC-containing sequences. Bailly and co-worker [4] has reported the recognition of the ATGA sequence by DB293 by using SPR technology "Fig. (7B, C)". The use of different hairpin oligonucleotides showed that DB293 can interact with AT sites via the formation of 1:1 drug-DNA complexes but binds much more strongly, and cooperatively, to ATGA-containing sequences to form $2: 1$ drug-DNA complexes. DB293 binds strongly to ATGA sequences with no significant context dependence, but is highly sensitive to the orientation of the target sequence. The formation of 2:1 DNA-DB293 complexes is abolished by reversing the sequence $5^{\prime}$-ATGA-3'-ATGA, indicating that directionality plays an important role in the drug-DNA recognition process. From the SPR data, the 5'-ATGA sequence was identified as being a highly favored dimer binding site for DB293. The data provide clues for delineating a recognition code for diamidine-type minor groove binding agents, and ultimately to guide the rational design of gene regulatory molecules targeted to specific sites of the genetic material.

Carrasco and co-worker [8] investigated the structural selectivity of the DNA-binding antitumor drug ditercalinium and a detailed analysis of the binding reaction of the drug, with four-stranded DNA structures which was performed by SPR method. The BIAcore SPR study showed that the kinetic parameters for the interaction of ditercalinium with the human telomeric quadruplex sequence are comparable to those measured with a duplex sequence. They proved that 
(A)<smiles>NC(=[NH2+])c1ccc(-c2ccc(-c3nc4cc(C(N)=[NH2+])ccc4[nH]3)o2)cc1</smiles>

DB293

(B)

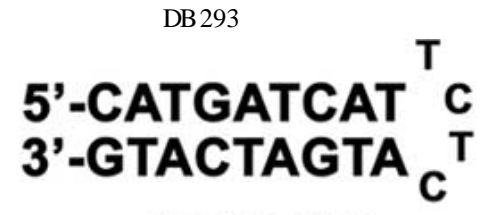

Oligo2-2 ATGA

(C)

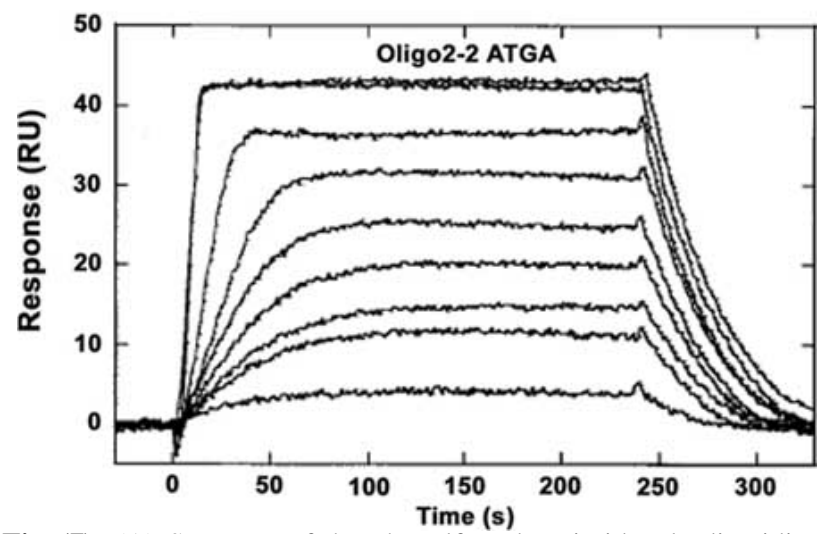

Fig. (7). (A) Structure of the phenylfuranbenzimidazole diamidine derivative DB293, which is in the DNA minor groove of GCcontaining sequences. (B) Oligonucleotide sequence (Oligo2-2 ATGA) for the DNA used in SPR binding experiment. (C) SPR sensorgram for binding of DB293 to the oligo2-2 ATGA sequence at $25{ }^{\circ} \mathrm{C}$. The unbound DB293 concentrations in the flow solutions range from $1 \mathrm{nM}$ in the lowest curve to $1 \mu \mathrm{M}$ in the top curve. MES buffer with $0.1 \mathrm{M} \mathrm{NaCl}$ was used in the SPR experiment. Adapted from [4].

binding of ditercalinium to the G4 tetraplex is stronger and of a different character compared to binding with the duplexes. The G4 tetraplex results require fitting with a nonequivalent two-site model. The higher binding constant, $K_{1}$, is $3 \times 10^{7} \mathrm{M}^{-1}$ and is approximately ten times greater than the second, lower binding constant, $K_{2}$. The presence of two binding sites, one significantly stronger than the other, agrees with the results for a number of other G4 binding compounds. The preferential binding of ditercalinium to the antiparallel quadruplex sequence $\mathrm{d}\left(\mathrm{AG}_{3}\left[\mathrm{~T}_{2} \mathrm{AG}_{3}\right]_{3}\right)$ provides new perspectives for the design of drugs that can bind to human telomeres.

\section{MULTISITE INTERACTION MODE}

\subsection{Data Analysis}

The sensorgrams (resonance units, RU, vs time) are collected with various concentrations of samples injected. The RU values are averaged over a period of time span in the steady state response region and are converted to $r$ (moles of drug bound per mole of target DNA) for binding analysis as previously described in section 6.1. The binding constants of the drugs to target DNA are obtained from fitting a plot of $r$ $v s$ drug concentration $C$. The plot is fitted with a one-, two-, three-, or four-site interaction model (for one-site model, $K_{2}$ $=K_{3}=K_{4}=0$; for two-site model, $K_{3}=K_{4}=0$; for three-site model, $K_{4}=0$ ) [7]:

$$
\begin{aligned}
& r=\left(K_{1} C+2 K_{1} K_{2} C^{2}+3 K_{1} K_{2} K_{3} C^{3}+4 K_{1} K_{2} K_{3} K_{4} C^{4}\right) /(1 \\
& \left.+K_{1} C+K_{1} K_{2} C^{2}+K_{1} K_{2} K_{3} C^{3}+K_{1} K_{2} K_{3} K_{4} C^{4}\right)
\end{aligned}
$$

\subsection{Examples}

Nguyen and co-worker [7] investigated the DNA interactions of a series of nine diphenylfuran dications related to the antiparasitic drug furamidine (DB75) to develop sequence-specific gene-regulatory small organic molecules. The furamidine DB75 compound fits snugly into the minor groove of DNA and interacts selectively with ATrich sequences. Two types of structural modifications were tested: the terminal amidine groups of DB75 were shifted from the para to the meta position, and the amidines were replaced with imidazoline or dimethyl-imidazoline groups. The interactions of these compounds with DNA and oligonucleotides were studied by a combination of biochemical and SPR techniques. Accurate binding measurements using the BIAcore SPR method revealed that all nine compounds bind with similar affinity to an immobilized GC sequence DNA hairpin, but exhibit very distinct affinities for the corresponding AT hairpin oligonucleotide. The SPR results were converted to plots of $r$ vs $C$ and fitted to determine the binding constants by Eq. [13]. As with the spectral results, the para-para compounds have quite different behavior with the AT sequence DNA than the other compounds or with any of the compounds and the GC DNA. The para-para compounds have one very strong binding site $\left(K>2 \times 10^{7} \mathrm{M}^{-1}\right)$ with the AT hairpin DNA, and this site has slower association and much slower dissociation kinetics than for the other compounds. Secondary binding to the AT sequence by the amidine derivatives is approximately 100 times weaker than the primary binding. All other compounds have weaker interactions and more similar $K$ values with both the AT and GC DNAs (all $K<1 \times 10^{7} \mathrm{M}^{-1}$ ) as well as faster association and dissociation kinetics. These studies provide a rationale to explain the relationships between sequence selectivity and mode of binding to DNA for unfused aromatic dications related to furamidine.

\section{MULTIPLE EQUIVALENT-SITE INTERACTION MODE}

\subsection{Data Analysis}

When the observed response $R$ values at high concentrations are greater than $R_{\max }$, it points to more than one binding site in these DNA sequences. The number of binding sites may be determined from Scatchard plots of $R / C$ vs $R$ plot (Eq. [4]) by a linear regression analysis. The $R_{\max }$ value is required to convert the observed response $(R)$ to the standard binding parameter $r$ (moles of drug bound/moles of target DNA), where $r=R / R_{\max }$. To obtain the binding 
constants, the results from the steady-state region are fitted with a multiple equivalent-site model, and Kaleidagraph is used for nonlinear least-squares optimization of the binding parameters [9-10]:

$r=n K_{A} C /\left(1+K_{A} C\right)$

where $K_{A}$, the microscopic association constant, is one variable to fit; $r$ represents the moles of bound drug per mole of target DNA; $C$ is the concentration of the drug in equilibrium with the complex and is fixed by the concentration in the flow solution; $n$ is the number of equivalent drug-binding sites on the target DNA and is an integer larger than one "Fig. (8A)".
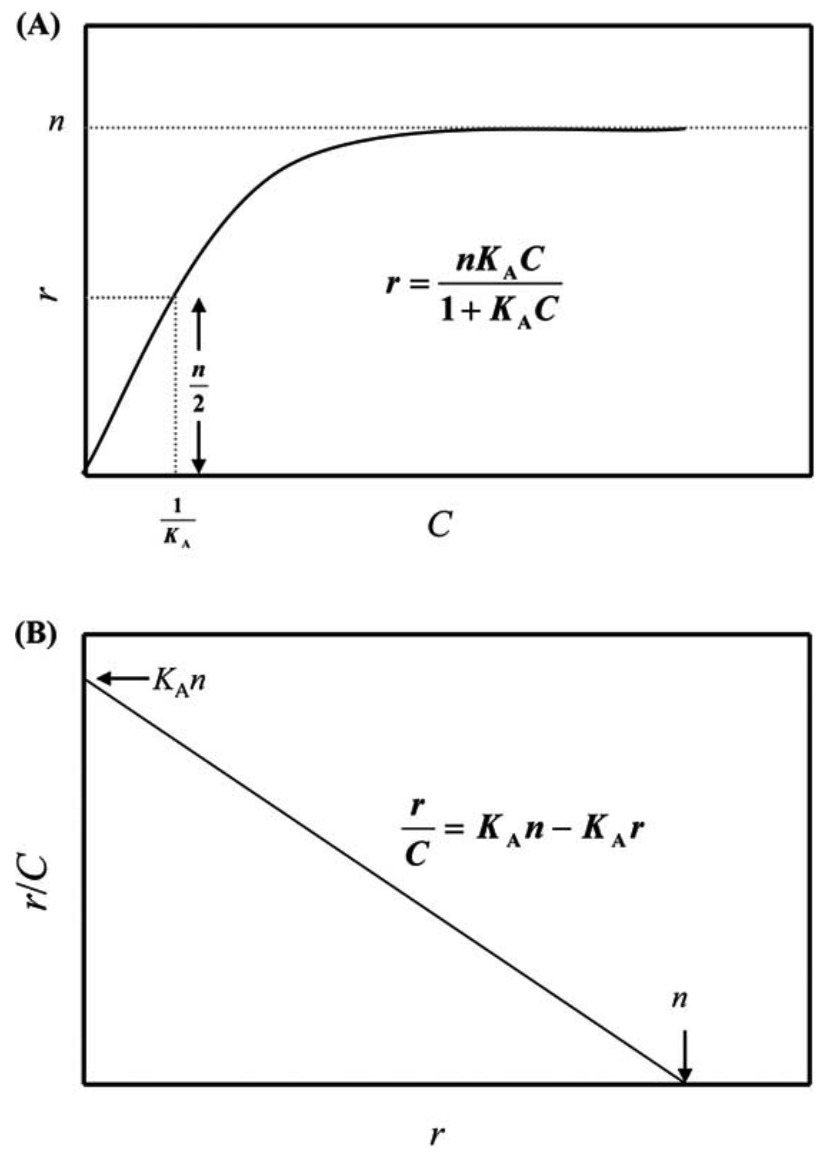

Fig. (8). (A) A binding curve of the number $r$ of equivalent binding sites on the DNA versus drug concentration $C$ according to Eq. [14]. (B) Scatchard binding plot ( $r / C$ vs $r$ ) according to Eq. [15] thus gives a straight line from which $n$ and $K_{\mathrm{A}}$ can be calculated.

Equation [14] can be rearranged:

$r / C=K_{\mathrm{A}} n-K_{\mathrm{A}} r$

Scatchard binding plot ( $r / C$ vs $r$ ) according to Eq. [15] is also usually used to determine the binding constant $K_{\mathrm{A}}$ and the number $n$ of equivalent binding sites on the DNA "Fig. (8B)".

\subsection{Examples}

Bilik and co-worker [5] report the interaction with DNA of two novel unfused aromatic dications derived from the antimicrobial agent furimidazoline. The central diphenylfuran core of furimidazoline has been replaced with a trithiophene (DB358) or a trifuran (DB669) unit and the terminal imidazoline groups were preserved. The interactions of the strong-binding trithiophene drug with three hairpin oligomers were determined by SPR methods. All binding curves were fit by nonlinear least squares to a model that assumed three approximately equal binding sites on the oligomers. Three sites are required by the magnitude of the SPR signal at high compound concentration. More complex fitting models did not result in any significant improvement in the quality of the fit. The binding constants obtained for DB358 are $1.7 \times 10^{6} \mathrm{M}^{-1}$ for the alternating AT oligomer, $1.4 \times 10^{6} \mathrm{M}^{-1}$ for the AATT sequence, and $0.6 \times 10^{6} \mathrm{M}^{-1}$ for the alternating GC sequence. The compounds, thus, exhibit a slight AT specificity.

Carrasco and co-workers [9] investigated the interaction of a disaccharide indolocarbazole derivative, AT2433-B1 "Fig. (9A)", with different DNA sequences by means of SPR technology. The antibiotic AT2433-B1 belongs to a therapeutically important class of antitumor agents. It contains a unique disaccharide consisting of a methoxyglucose and an amino sugar subunit, 2,4-dideoxy-4methylamino-L-xylose. To evaluate the sequence selectivity of the antitumor drug, DNA hairpin oligomers with either an alternating $[\mathrm{CG}]_{4}$ or $[\mathrm{AT}]_{4}$ base pair duplex sequence were immobilized on BIAcore SA sensorchips and SPR experiments with AT2433-B1 were conducted at 4 and $25^{\circ} \mathrm{C}$. A typical set of sensorgrams at different drug concentrations for AT2433-B1 binding to the AT and GC oligomers was obtained "Fig. (9B, C)". Accurate binding measurements revealed that AT2433-B1 binds considerately more tightly to a DNA hairpin oligomer containing a $[\mathrm{CG}]_{4}$ block, than to an oligomer with a central $[\mathrm{AT}]_{4}$ tract "Fig. (9D)". Equilibrium binding constants of $13 \times 10^{5}$ and $89 \times 10^{5} \mathrm{M}^{-1}$ were also determined at 4 and $25^{\circ} \mathrm{C}$ with the AT and GC sequences, respectively (Table 1). Not only does AT2433-B1 exhibit a significant preference for the GC target, but it binds to DNA with high affinity. The results indicate that this natural product bind strongly to DNA, which can therefore be considered as a potential target through which the drug exerts its cytotoxic activity. The selective interaction with GC-rich sequences may play a role in the mode of action of this compound. Upon binding to GC sites, the drug is likely to interfere with DNA-reactive enzymes such as polymerases and transcription factors.

Teulad-Fichou and co-worker [10] investigated the interaction of G-quadruplex DNA with the macrocyclic compound BOQ1 that possesses two dibenzophenanthroline (quinacridine) subunits by SPR methods. They used the oligonucleotide 5'-A(GGGT $\left.{ }_{2} \mathrm{~A}\right)_{3} \mathrm{G}_{3}$ as one model system, which mimics the human telomeric repeat sequence and forms an intramolecular quadruplex. The binding affinity and stoichiometry of the macrocycle to quadruplex and duplex DNAs was evaluated with more detailed studies by biosensor-SPR methods. Values for stoichiometry have arisen naturally from the SPR results through analysis of the maximum RU values observed as saturating concentrations of the compound with the target DNA sequence were approached. The SPR results indicated two essentially equi- 


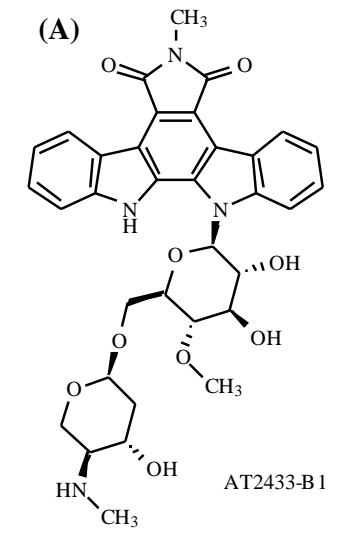

(C)

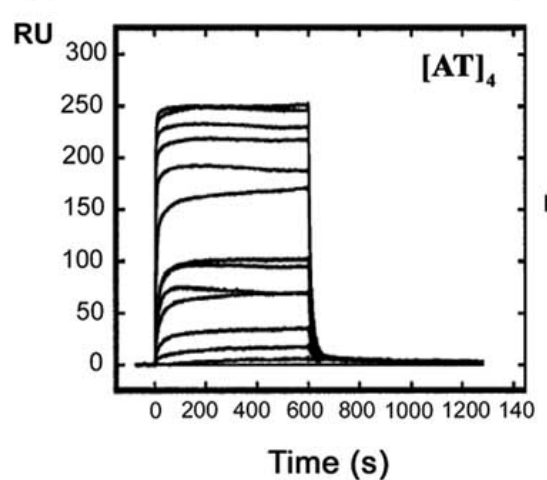

(B)

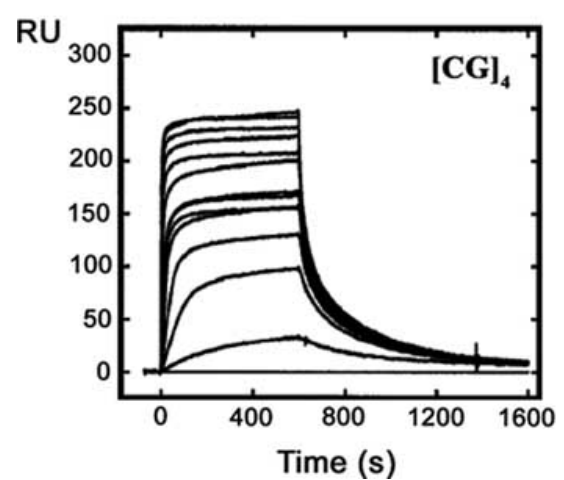

(D)

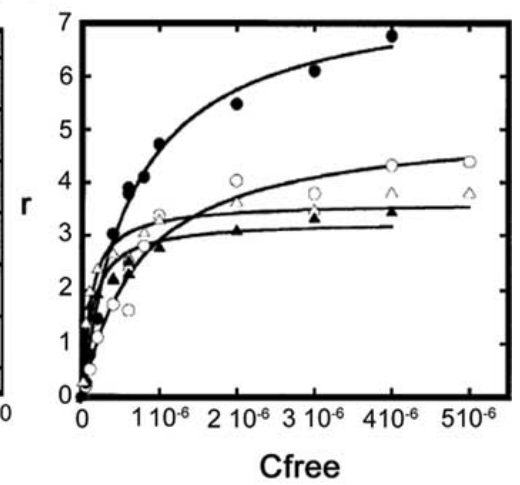

Fig. (9). (A) Structure of the indolocarbazole compound rebeccamycin AT2433-B1. (B, C) SPR sensorgrams for binding of AT2433-B1 to the $[\mathrm{AT}] 4$ and [CG]4 DNA hairpin oligomers, respectively, in HBS-EP buffer at 25oC. The concentration of the unbound ligand in the flow solution varies from $10 \mathrm{nM}$ in the lowest curve to $4 \_\mathrm{M}$ in the top curve. (D) Binding plots used to determine the affinity constants for AT2433-B1 complexed with the $[\mathrm{AT}]_{4}$ and $[\mathrm{CG}]_{4}$ sequences. To construct these plots, RU values from the steady-state region of the SPR sensorgrams presented in (B) and (C) were converted to $r$ (mol drug bound per mol DNA hairpin) and plotted versus the concentration of unbound AT2433-B1 molecules. Circles and triangles refer to the AT and GC sequences and the open and filled symbols correspond to experiments performed at 25 and $4{ }^{\circ} \mathrm{C}$, respectively. Adapted from [9].

valent binding sites for the macrocycle with quadruplexes based on the human telomere. SPR results predicted a BOQ1 binding constant of $107 \mathrm{M}-1$ or larger for the human quadruplex sequence. Binding constants for the monomer control compounds are around a factor of 10 lower for the human G4 sequence than for BOQ1. The monomers and the macrocycle have similar binding constants with duplex DNAs, however, and the macrocycle thus has much greater quadruplex binding specificity. In addition, the macrocycle is more selective than the monomeric control compound (MOQ2), which is not able to discriminate between the two DNA structures ( Kduplex Kquadruplex 106 M-1).

\section{CONCLUDING REMARKS}

The SPR techniques can be used at two levels of biomolecular interaction analysis. Firstly, in providing simple yes/no answers to the question: Does drug bind to DNA? Secondly, they can, with care, provide accurate binding affinity and stoichiometry data. Both methods are sensitive to the binding of mass to an activated optical sensor chip surface. The literatures surveyed in this review demonstrate that SPR can successfully detect and quantitate binding of small molecule of drug to DNA sequence by three different mechanisms, intercalation, minor groove binding, and electrostatics. The association constants measured ranged from $10^{4}$ (low affinity) to $10^{7}$ (medium affinity) $\mathrm{M}^{-1}$. This methodology may prove to be useful in drug development and serve as an assay for DNA binding ability. Direct real-time observation and measurement of the interaction between potential drug and target DNA is a subject of interest for drug discovery and development in the future.

\section{ABBREVIATIONS}

SPR $=$ Surface plasmon resonance

$K_{\mathrm{D}}=$ Dissociation constant

$k_{\mathrm{a}}=$ Association rate constant

$k_{\mathrm{d}}=$ Dissociation rate constant

\section{REFERENCES}

[1] Tanious, F.A.; Ding, D; Patrick, D.A.; Bailly, C.; Tidwell, R.R. and Wilson, W.D. (2000) Biochemistry, 39(39), 12091-12101.

[2] Wang, L.; Bailly, C.; Kumar, A.; Ding, D; Bajic, M.; Boykin, D.W. and Wilson, W.D. (2000) Proc. Natl. Acad. Sci. USA, 97(1), 12-16. 
[3] Tanious, F.A.; Wilson, W.D.; Patrick, D.A.; Tidwell, R.R.; Colson, P.; Houssier, C.; Tardy, C. and Bailly, C. (2001) Eur. J. Biochem ., 268(12), 3455-3464.

[4] Bailly, C.; Tardy, C.; Wang, L.; Armitage, B.; Hopkins, K.; Kumar, A.; Schuster, G.B.; Boykin, D.W. and Wilson, W.D. (2001) Biochemistry, 40(33), 9770-9779.

[5] Bilik, P.; Tanious, F.; Kumar, A.; Wilson, W.D.; Boykin, D.W.; Colson, P.; Houssier, C.; Facompre, M.; Tardy, C. and Bailly, C. (2001) Chembiochem., 2(7-8), 559-569.

[6] Wang, L.; Carrasco, C.; Kumar, A.; Stephens, C.E.; Bailly, C.; Boykin, D.W. and Wilson, W.D. (2001) Biochemistry, 40(8), 25112521.

[7] Nguyen, B.; Tardy, C.; Bailly, C.; Colson, P.; Houssier, C.; Kumar, A.; Boykin, D.W. and Wilson, W.D. (2002) Biopolymers, 63(5), 281-297.

[8] Carrasco, C.; Rosu, F.; Gabelica, V.; Houssier, C.; Pauw, E.D.; Garbay-Jaureguiberry, C.; Roques, B.; Wilson, W.D.; Chaires, J.B.; Waring, M.J. and Bailly, C. (2002) Chembiochem., 3(12), 12351241.

[9] Carrasco, C.; Facompré, M.; Chisholm, J.D.; Vranken, D.L.V.; Wilson, W.D. and Bailly, C. (2002) Nucleic Acids Res., 30(8), 1774-1781.

[10] Teulade-Fichou, M.P.; Carrasco, C.; Guittat, L.; Bailly, C.; Alberti, P.; Mergny, J.L.; David, A.; Lehn, J.M. and Wilson, W.D. (2003) J. Am. Chem. Soc., 125(16), 4732-4740.

[11] Davidson, M. (1992) Spectroscopy, 7(1), 32-36.

[12] Feriotto, G.; Ciucci, A.; Mischiati, C.; Animati, F.; Lombardi, P.; Giacomini, P. and Gambari, R. (1994a) Eur. J. Pharmacol., 267(2), 143-149.

[13] Mischiati, C.; Borgatti, M. and Bianchi, N. (1999) J. Biol. Chem., 274(46), 33114-33122.

[14] Agbandje, M. and McKenna, R. (1992) In Nucleic Acid Targeted Drug Design, (Propst, C.L. and Perun, T.J., Ed.), Marcel Dekker, New York, pp. 525-551.

[15] Dabrowiak, J.C.; Stankus, A.A. and Goodisman, J. (1992) In Nucleic Acid Targeted Drug Design, (Propst, C.L. and Perun, T.J., Ed.), Marcel Dekker, New York, pp. 128.

[16] Davies, J. (1994) Nanobiology, 3(1), 5-16.
[17] Markey, F. (1999) BIA J., 6(1), 14-17.

[18] Lackmann, M.; Bucci, T.; Mann, R.J.; Kravets, L.A.; Viney, E.; Smith, F.; Moritz, R.L.; Carter, W.; Simpson, R.J. and Nicola, N.A. (1996) Proc. Natl. Acad. Sci. USA, 93(6), 2523-2527.

[19] Myszka, D.G. (1999) J. Mol. Recognit., 12(6), 390-408.

[20] Rich, R.L. and Myszka, D.G. (2000) Curr. Opin. Biotech., 11(1), 54-61.

[21] Markgren, P.-O.; Hämäläinen, M. and Danielson, U. (1999) Anal. Biochem., 265(2), 340-350.

[22] Morton, T.A. and Myszka, D.G. (1998) Methods Enzymol., 295, 268-294.

[23] Myszka, D.G.; Jonsen, M.D. and Graves, B.J. (1998) Anal. Biochem., 265(2), 326-330.

[24] Zeder-Lutz, G.; Neurath, A.R. and Van Regenmortel, M.H. (1999) Biologicals, 27(1), 29-34.

[25] Roos, H.; Karlsson, R.; Nilshans, H. and Persson, A. (1998) J. Mol. Recognit., 11(1-6), 204-210.

[26] Gambari, R.; Feriotto, G.; Rutigliano, C.; Bianchi, N. and Mischiati, C. (2000) J. Pharmacol. Exp. Ther., 294(1), 370-377.

[27] Ciolkowski, M.L.; Fang, M.M. and Lund, M.E. (2000) J. Pharm Biomed. Anal., 22(6), 1037-1045.

[28] Boger, D.L. and Saionz, K.W. (1999) Bioorg. Med. Chem., 7(2), 315-321.

[29] Read, M.; Harrison, R.J.; Romagnoli, B.; Tanious, F.A.; Gowan, S.H.; Reszka, A.P.; Wilson, W.D.; Kelland, L.R. and Neidle S. (2001) Proc. Natl. Acad. Sci. USA, 98(9), 4844-4849.

[30] Glaser, R.W. (1993) Analyt. Biochem., 213(1), 152-161.

[31] Jonsson, U.; Fagerstam, L.; Ivarsson, B.; Johnsson, B. and Karlsson, R. (1991) Biotechniques, 11(5), 620-627.

[32] Vadgama, P. and Crump, P.W. (1992) Analyst, 117(11), 1657-1670.

[33] Malmqvist, M. (1993) Nature (Lond), 361(6408), 186-187.

[34] Persson, B.; Stenhag, K.; Nilsson, P.; Larsson, A.; Uhle'n, M. and Nygren, P. (1997) Anal. Biochem., 246(1), 34-44.

[35] Chen, F.M. (1988) Biochemistry, 27(17), 6393-6397.

[36] Chen, F.M. (1992) Biochemistry, 31(27), 6223-6228.

[37] Mazur, S.; Tanious, F.A.; Ding, D.; Kumar, A.; Boykin, D.W.; Simpson, I.J.; Neidle, S. and Wilson, W.D. (2000) J. Mol. Biol., 300(2), 321-337. 